\title{
Safety and Efficacy of Tafenoquine for Plasmodium vivax Malaria Prophylaxis and Radical Cure: Overview and Perspectives
}

\author{
Miles B Markus $\mathbb{D}^{1,2}$ \\ 'School of Animal, Plant and \\ Environmental Sciences, Faculty of \\ Science, University of the \\ Witwatersrand, Johannesburg, South \\ Africa; ${ }^{2}$ Wits Research Institute for \\ Malaria, School of Pathology, Faculty of \\ Health Sciences, University of the \\ Witwatersrand, Johannesburg, South \\ Africa
}

Correspondence: Miles B Markus Wits Research Institute for Malaria, School of Pathology, Faculty of Health Sciences, University of the

Witwatersrand, 7 York Road, Parktown, Johannesburg, 2193, South Africa

Tel +27794580773

Fax +27 I I 7892950

Email medsynth@yahoo.co.uk

\begin{abstract}
This article is inter alia a brief, first-stop guide to possible adverse events (AEs) associated with tafenoquine (TQ) intake. Safety and efficacy findings for TQ in Plasmodium vivax malaria prophylaxis and radical cure are summarized and some of the latest TQ-related studies (published in 2020 and 2021) are highlighted. In addition, little-known biological and other matters concerning malaria parasites and 8-aminoquinoline (8-AQ) drug action are discussed and some correct terminology pertinent to malaria is explained.
\end{abstract}

Keywords: chloroquine, G6PD, hypnozoite, primaquine, relapse, WR238605

\section{Introduction}

Tafenoquine (TQ) is an antimalarial drug of the 8-aminoquinoline (8-AQ) class. ${ }^{1,2}$ A single oral dose is more often than not effective for the radical cure of Plasmodium vivax malaria. TQ is thought to prevent malarial recurrence by killing a dormant plasmodial stage in the liver, for which I coined the term "hypnozoite" more than four decades ago. ${ }^{3-5}$ On the basis of my research at Imperial College London on an organism related to malaria parasites, I thought it likely ${ }^{6}$ that a hypnozoite stage exists in the life cycle of Plasmodium, and this turned out to be the case. ${ }^{7}$

Ever since 1980, it has traditionally been stated by malariologists as a fact that hypnozoites are the source of relapse in $P$. vivax malaria. Despite this assumption, only recently have hypnozoites actually been shown to activate. The first researchers to demonstrate this were Voorberg-van der Wel et al, ${ }^{8,9}$ using the primate model organism P. cynomolgi. The factors that account for hypnozoite formation and activation are unknown, giving rise to much speculation. ${ }^{10}$ Whether $P$. vivax sporozoites can persist anywhere extra-hepatically (as hypnozoites do in the liver) and be a source of malarial recurrence is not known. ${ }^{1,12}$ Like other aspects of early post-invasion plasmodial biology, ${ }^{13}$ this theoretical possibility has been insufficiently investigated. Gametocytes of Plasmodium occur dermally in humans, although significant sequestration there has not been detected. ${ }^{14}$ TQ will not necessarily eliminate $P$. vivax sporozoites or merozoites if they are present in human skin, extrapolating from what has been shown in rodent malaria for primaquine. $^{15-17}$

The most widespread cause of human malaria globally is $P$. vivax, ${ }^{18}$ the other common etiological agent being $P$. falciparum. One of the ways in which the 
biology of $P$. vivax differs ${ }^{19-21}$ from that of $P$. falciparum is that the latter does not seem to occur in a hypnozoite form. P. vivax-like recurrences sometimes take place in humans infected with $P$. ovale curtisi and $P$. ovale wallikeri. $^{22}$ It has therefore been widely assumed that hypnozoites are the origin of such recurrences, but persisting hypnozoites have not (yet) been shown to exist in the life cycle of $P$. o. curtisi or $P$. o. wallikeri. ${ }^{23-28}$ The effect of TQ in the prophylaxis and treatment of $P$. o. curtisi and $P$. o. wallikeri malaria is unknown (and evidence to support the use of its sister drug primaquine is limited ${ }^{27,29}$ ). Consequently, this article is only about TQ in relation to P. vivax malaria.

\section{Terminology}

The terms "recurrence", "recrudescence" and "relapse" are used here. A malarial recurrence is a re-infection, a recrudescence or a relapse. Thus, all three are covered by the word "recurrence". More specifically, a recrudescence has a merozoite origin and a relapse has a hypnozoite origin. The definition of "recrudescence" as renewed parasitemia or clinical manifestations resulting from the multiplication of bloodstream parasites following failed drug treatment is out of date, because extravascular and sequestered merozoites are probably also sources of $P$. vivax malarial recrudescences. I introduced this noncirculating parasite theory ${ }^{30,31}$ regarding the source of P. vivax malarial recurrences ten years ago. Also, the implications of the presumed presence of these particular stages for the elimination of malaria were pointed out for the first time. ${ }^{30}$ That introduction was the theory's sole origin (see Table 1 in Markus ${ }^{31}$ ) in the post-hypnozoitediscovery era. The theory was not reiterated by anyone else during the ensuing seven years. This bit of recent history has in the meantime been obfuscated in a few publications by other authors. In those articles, citations which would have been appropriate are conspicuous by their absence. That aside, it is important to be aware that amongst the published literature on malaria are numerous papers (both old and new) in which some recurrences interpreted as relapses of $P$. vivax malaria are likely to have been non-circulating merozoite-initiated recrudescences.

Imprecise language should be avoided when discussing the drug treatment of malaria. ${ }^{32}$ For example, hypnozoites do not relapse - they activate. It is the infection that relapses (the patient suffers a relapse). However, we should not refer to a "relapse infection", since it is still the same infection. "Relapse infection" means a new infection. So instead, say "relapsed infection" or "relapsing infection". We do not "treat" or "cure" hypnozoites with TQ - they are destroyed, eliminated, inactivated or killed. We treat or cure the patient who has malaria, not the hypnozoites. Likewise, we do not "treat $P$. vivax" or "cure P. vivax", those being the expressions which are sometimes used. In the therapeutic sense of "treat" (unlike "treating" cell cultures or mosquito nets, for instance), it is not the parasite that is treated but the disease or the patient. Thus, we "treat $P$. vivax malaria" or "cure $P$. vivax malaria". The term "malaria(s)" should not be used to refer to one or more species of Plasmodium, only to the disease (malaria). For example, it is seriously incorrect to call a species of Plasmodium "a malaria" 32 or to talk about the "malaria life cycle". And note that Plasmodium does not have a plural "Plasmodia". ${ }^{33}$ For the plural, we must write "Plasmodium species"; or "Plasmodium spp."; or "species of Plasmodium"; or "plasmodial species". The adjective "plasmodial" is correct. Mistakes like those mentioned above are common in the literature ${ }^{32,33}$ but the repetition does not make them correct.

Attention needs to be paid to all of this terminology if we are to avoid perpetuating technical errors in publications on antimalarial drugs.

\section{Tafenoquine Action}

TQ seems to have a marked hypnozoite-killing effect. We now need to ascertain the extent to which, if at all, this apparent anti-relapse activity of TQ (both alone and in combination with chloroquine) can be ascribed to elimination of non-circulating merozoites. ${ }^{34}$ Asexual P. vivax stages that have not been phagocytosed occur in the human spleen in huge numbers, ${ }^{35-37}$ something not previously known. As had been suspected, ${ }^{30,38,39}$ they are also constantly present in the bone marrow of infected humans and non-human primates. ${ }^{40-43}$ In comparison with the number of merozoites in the human spleen and also in bone marrow, the number of hypnozoites in the liver is very small. Non-circulating asexual parasites are likely to occur elsewhere too in chronic human $P$. vivax infections their distribution not being restricted to just the spleen and bone marrow. To quote a decade-old, essentially predictive statement:

Malariologists need to reassess the conventional view that plasmodial habitats in humans are only liver and blood and 
Table I Common Adverse Events (Regardless of Causality) in Some Prophylaxis Studies, Correlated with Tafenoquine Dosage (Information from Papers Additional to Those Cited in the "Adverse Events" Section)

\begin{tabular}{|c|c|c|c|}
\hline Adverse Event Details & Drug Dosage & $\begin{array}{l}\text { Number of } \\
\text { Individuals }\end{array}$ & $\begin{array}{l}\text { Reference } \\
\text { Number }\end{array}$ \\
\hline AEs reported: abdominal pain; headache; fever; fatigue & $\begin{array}{l}250 \mathrm{mg} / \mathrm{d} \text { for } 3 \mathrm{~d} \text { (highest } \\
\text { dosage tested) }\end{array}$ & 84 & {$[100]$} \\
\hline $\begin{array}{l}\geq 5 \% \text { AEs (detailed breakdown given in the paper }{ }^{101} \text { ): Gl } 46 \text {; respiratory } 39 \text {; } \\
\text { neurologic } 25 \text {; dermatologic } 22 \text {; MS } 20\end{array}$ & $\begin{array}{l}400 \mathrm{mg} / \mathrm{d} \text { for } 3 \mathrm{~d}+400 \mathrm{mg} / \\
\mathrm{w} \text { for } 13 \mathrm{w} \text { (highest dosage } \\
\text { tested) }\end{array}$ & 59 & {$[101]$} \\
\hline Only mild and transient AEs (diarrhea and headache) reported & $\begin{array}{l}400 \mathrm{mg} / \mathrm{d} \text { for } 3 \mathrm{~d}+400 \mathrm{mg} / \\
\mathrm{m} \text { for } 5 \mathrm{~m}\end{array}$ & 104 & {$[102]$} \\
\hline $\begin{array}{l}\geq 5 \% \text { AEs: RTI 14.4; myalgia 13.4; diarrhea 12.4; back pain 6.2; arthralgia 5.I; } \\
\text { gastritis 5.I }\end{array}$ & $\begin{array}{l}200 \mathrm{mg} / \mathrm{w} \text { for } 12 \mathrm{w} \text { (highest } \\
\text { dosage tested) }\end{array}$ & 93 & [103] \\
\hline AEs: mild I3.7; moderate 1.0 ; severe 0.2 & $\begin{array}{l}200 \mathrm{mg} / \mathrm{d} \text { for } 3 \mathrm{~d}+200 \mathrm{mg} / \\
\mathrm{w} \text { for } 6 \mathrm{~m}\end{array}$ & 490 & {$[104]$} \\
\hline $\begin{array}{l}\geq 5 \% \text { AEs: URTI 2I; diarrhea I6; back pain I5; rash I4; headache I2; arthralgia II; } \\
\text { fungal dermatitis 9; viral infection 8; nausea 6; abdominal pain 5; pharyngitis } 5\end{array}$ & $200 \mathrm{mg} / \mathrm{w}$ for $6 \mathrm{~m}$ & 492 & {$[105]$} \\
\hline
\end{tabular}

Notes: The figures for adverse events (AEs) are percentages. AEs that have frequently been recorded are shown. For the full range of possible AEs, see the paper concerned.

Abbreviations: AE, adverse event; d, day(s); GI, gastrointestinal; m, month(s); mg, milligrams; MS, musculoskeletal; RTI, respiratory tract infection; URTI, upper respiratory tract infection; w, week(s).

be more open to the concept of there perhaps being additional parasite reservoirs. ${ }^{44}$

Furthermore, "much remains to be learnt about clinically relevant aspects of the basic biology of human malaria parasites." $" 44$

Administration of primaquine for malaria produces hydrogen peroxide in the bone marrow. ${ }^{45}$ This will presumably inactivate an unknown proportion of plasmodial stages there, including $P$. falciparum gametocytes. It has been suggested ${ }^{34}$ that, by analogy, asexual parasites and gametocytes in bone marrow could conceivably also be killed when TQ is used for the radical cure of $P$. vivax malaria. The possibility has not been investigated, however. Another unanswered question is whether or not drug synergism $^{46-48}$ (especially TQ + chloroquine) intensifies the destruction of non-circulating merozoites anywhere in the body. ${ }^{34}$ Interpretation of in vivo findings in this regard could be difficult, partly because it is often not clear to what extent malarial recurrences might be the result of drug-resistant $P$. vivax ${ }^{49-51}$ (something that is better understood for $P$. falciparum, however ${ }^{52,53}$ ).

As mentioned above in the section on terminology, many of the recurrences in patients with $P$. vivax malaria are now believed to be recrudescences (as opposed to relapses) with an extravascular or sequestered merozoite origin. $^{30,31}$ Even some late (post-28-days) homologous recurrences are thought to be recrudescences. ${ }^{30,31,51}$ This realization has called into question the rule of thumb that pre-28-day recurrences are more likely to be recrudescences and post-28-day recurrences are more likely to be relapses. That idea is based largely on information about drug levels in the bloodstream. Whereas many post-28-day recurrences will no doubt indeed be relapses, it is also possible, if not likely, ${ }^{30}$ that some long-term recurrences of $P$. vivax malaria have the same presumed non-hypnozoite origin as long-term recurrences of $P$. malariae infection ( $P$. malariae is not known to have a hypnozoite form), whatever the non-hypnozoite origin concerned may be. $^{30,54-56}$ For that matter, presumed non-hypnozoite $P$. falciparum and $P$. ovale sensu lato parasites can persist for long periods too. ${ }^{54,57,58}$

To summarize, the point being made above is that, as I recently hypothesized elsewhere, ${ }^{34}$ TQ may help to prevent not only hypnozoite-derived relapses but possibly also recrudescences which have a splenic, bone marrow, or some other non-circulating merozoite origin. Besides its likely anti-relapse action, TQ is indeed known to eliminate parasite stages that are not hypnozoites. ${ }^{59,60}$ When used 
prophylactically, it might do so before schizogony can take place in the liver.

\section{Tafenoquine and Glucose-6-Phosphate- Dehydrogenase Deficiency}

A major obstacle to treating P. vivax malaria with TQ (and other 8-AQs like the related, older and ubiquitously used drug primaquine ${ }^{61}$ ) or using TQ for prophylaxis is the danger of severe and life-threatening hemolysis associated with glucose-6-phosphate-dehydrogenase (G6PD) deficiency. This is a chromosomally X-linked disorder and a fairly common inherited enzymopathy. ${ }^{62}$ Testing for G6PD deficiency is required before TQ (or any other 8-AQ) can be taken. Accordingly, health care workers in P. vivax-endemic rural areas must be trained in G6PD testing. ${ }^{63-65}$ The diagnosis of G6PD deficiency can be especially tricky in heterozygous women because of random X-chromosome inactivation.

A reliable quantitative G6PD deficiency-related cut-off point is required in order to decide whether TQ can be used safely. ${ }^{66-68}$ Calvaresi and Genzen ${ }^{69}$ propose that retrospective analysis of a laboratory's data set might help to evaluate eligibility for malaria prophylaxis or radical cure treatment with TQ. A 100\% normal G6PD activity reference value would be determined and then the individual's activity result would be converted to a percentage of that laboratory-specific normal activity. ${ }^{69}$ As the results of spectrophotometry to measure G6PD activity vary widely between laboratories, study findings are often not comparable. In considering this variability, Pfeffer et $\mathrm{al}^{70}$ conclude that novel handheld quantitative G6PD diagnostics might facilitate future standardization.

Other laboratory matters require investigation too. One suggestion, by Boonyuen et al, ${ }^{71}$ is that a newly developed and simplified high resolution melting curve assay, which has $100 \%$ specificity and $100 \%$ sensitivity, could be helpful as a supplementary approach to high-throughput screening, particularly for heterozygous females.

Also important to take into account is the effect of different blood storage conditions on the results of poststorage screening for G6PD deficiency. It is obviously vital that the level of G6PD deficiency be accurately determined, safety being at stake if TQ is to be used. With this in mind, Chamchoy et $\mathrm{al}^{72}$ used the WST-8 assay to evaluate the consequences of storage of blood samples. Their conclusions will probably be applicable to other G6PD tests as well, although this is subject to confirmation. They found that activity in G6PD-deficient specimens decreased markedly under all the storage conditions they studied, although G6PD classification was not affected. They offer advice about the storage of both dried blood spots and ethylenediaminetetraacetic acid (EDTA) whole blood specimens.

\section{Contraindications, Precautions and Warnings}

TQ for malaria prophylaxis or radical curative therapy should not be taken by anybody whose G6PD status is not known; or by a breastfeeding mother if the infant is G6PD-deficient or its G6PD status is unknown. Use of TQ in pregnancy is not recommended. TQ is contraindicated for individuals with known hypersensitivity to 8-AQs. Use of TQ by persons with a current psychiatric illness or a history of psychosis is potentially problematic, and caution is advised. ${ }^{73,74}$ Lastly, medical treatment is required if signs or symptoms of methemoglobinemia occur.

\section{Adverse Events}

TQ is generally well tolerated but adverse events (AEs) can take place. As there is almost total overlap between the kinds of AEs that may follow prophylaxis and those that may follow radical curative treatment, they are first dealt with together here and then specific safety issues for each are covered separately in the next two sections of the article as well as in Tables 1-3.

TQ-related AEs are almost always mild and selfresolving. However, there can be severe reactions in cases of G6PD deficiency. In some studies, AEs occurred more often in people who received higher doses of TQ, as were given in some drug trials. In other studies, no correlation was found between dosages and the frequency of AEs.

\section{Central Nervous System}

Rodent, canine and non-human primate drug studies suggest that TQ is unlikely to cause serious central nervous system problems in humans. ${ }^{75,76} \mathrm{TQ}$ is not classed as neurotoxic in humans at prophylactic doses. ${ }^{75}$ In patients with no mental disorder history, only self-limiting and mild-to-moderate central nervous system AEs have been observed after a single $300 \mathrm{mg}$ radical cure dose of TQ combined with chloroquine. 
Table 2 Common Adverse Events (Regardless of Causality) in Post-Exposure Prophylaxis Studies, Correlated with Tafenoquine Dosage and Gender (Information from Papers Additional to Those Cited in the "Adverse Events" Section)

\begin{tabular}{|c|c|c|c|}
\hline Adverse Event Details & Drug Dosage & $\begin{array}{l}\text { Number of } \\
\text { Individuals }\end{array}$ & $\begin{array}{l}\text { Reference } \\
\text { Number }\end{array}$ \\
\hline$\geq 5 \%$ AEs: nausea 27; abdominal cramps 9; diarrhea 10 ; headache 5 & $400 \mathrm{mg} / \mathrm{d}$ (single dose) for $3 \mathrm{~d}$ & 254 males & {$[106]$} \\
\hline $\begin{array}{l}\geq 5 \% \text { AEs: nausea } 53 \text {; abdominal cramps } 26 \text {; diarrhea } 8 \text {; vomiting } \\
16 \text {; headache II; lethargy } 5\end{array}$ & $400 \mathrm{mg} / \mathrm{d}$ (single dose) for $3 \mathrm{~d}$ & 38 females & {$[106]$} \\
\hline$\geq 5 \%$ AEs: nausea 19; abdominal cramps II; diarrhea 16 & $200 \mathrm{mg} 2 \times / \mathrm{d}$ for $3 \mathrm{~d}$ & 73 males & {$[106]$} \\
\hline $\begin{array}{l}\geq 5 \% \text { AEs: nausea } 38 \text {; abdominal cramps } 23 \text {; diarrhea } 8 \text {; headache } \\
8 \text {; lethargy I5 }\end{array}$ & $200 \mathrm{mg} 2 \times / \mathrm{d}$ for $3 \mathrm{~d}$ & 13 females & {$[106]$} \\
\hline $\begin{array}{l}\geq 5 \% \text { GI AEs: abdominal distress } 13.2 \text {; diarrhea } 14.5 \text {; nausea } 3 \text { I.6; } \\
\text { reflux I5.8; vomiting } 5.3\end{array}$ & $400 \mathrm{mg} / \mathrm{d}$ (single dose) for $3 \mathrm{~d}$ & 76 males & {$[107]$} \\
\hline $\begin{array}{l}\geq 5 \% \text { GI AEs: abdominal distress } 54.5 \text {; diarrhea } 27.3 \text {; nausea } 72.7 \text {; } \\
\text { reflux 18.2; vomiting } 9.1\end{array}$ & $400 \mathrm{mg} / \mathrm{d}$ (single dose) for $3 \mathrm{~d}$ & II females & {$[107]$} \\
\hline $\begin{array}{l}\geq 5 \% \text { GI AEs: abdominal distress } 6.8 \text {; diarrhea } 21.9 \text {; nausea } 21.9 \text {; } \\
\text { reflux 5.5; vomiting } 21.9\end{array}$ & $200 \mathrm{mg} 2 \mathrm{x} / \mathrm{d}$ for $3 \mathrm{~d}$ & 73 males & {$[107]$} \\
\hline $\begin{array}{l}\geq 5 \% \text { GI AEs: abdominal distress } 15.4 \text {; diarrhea } 15.4 \text {; nausea } 46.2 \text {; } \\
\text { reflux } 23.1\end{array}$ & $200 \mathrm{mg} 2 \times / \mathrm{d}$ for $3 \mathrm{~d}$ & 13 females & {$[107]$} \\
\hline $\begin{array}{l}\geq 5 \% \text { AEs: nausea } 25.6 \text {; abdominal distress } 17.4 \text {; diarrhea } 9.5 \text {; } \\
\text { headache } 7.4 \text {; reflux } 5.8\end{array}$ & $\begin{array}{l}400 \mathrm{mg} / \mathrm{d} \text { (single dose) for } 3 \mathrm{~d} \text { (highest } \\
\text { dosage tested) }\end{array}$ & 242 & [108] \\
\hline $\begin{array}{l}\geq 5 \% \text { AEs: nausea 19.3; diarrhea } 14.9 \text {; abdominal distress } 10.6 \text {; } \\
\text { reflux } 6.2\end{array}$ & $\begin{array}{l}200 \mathrm{mg} 2 \mathrm{x} / \mathrm{d} \text { for } 3 \mathrm{~d} \text { (highest dosage } \\
\text { tested) }\end{array}$ & 161 & {$[108]$} \\
\hline
\end{tabular}

Notes: The figures for adverse events (AEs) are percentages (GI AEs are reported less often when TQ is taken after a meal). AEs that have frequently been recorded are shown. For the full range of possible AEs, see the paper concerned.

Abbreviations: AE, adverse event; d, day(s); GI, gastrointestinal; mg, milligrams.

\section{Eyes}

Reassuringly, no conclusive evidence of short-term ocular toxicity of clinical significance has been found in patients who received a single therapeutic dose of $300 \mathrm{mg}$ of TQ, ${ }^{77}$ nor in individuals who took $400 \mathrm{mg} /$ day for three days. ${ }^{78}$ Some minor and temporary ophthalmic changes were recorded, ${ }^{77,78}$ as other authors have reported too. ${ }^{73}$ In one study, no clinically significant ocular effects were detected at a dosing regimen of $200 \mathrm{mg}$ of TQ daily for three consecutive days (this being a $600 \mathrm{mg}$ loading dose), followed by $200 \mathrm{mg}$ once weekly for 23 weeks. ${ }^{79}$

\section{Heart}

There is no convincing evidence for cardiac toxicity. ${ }^{73,80,81}$

\section{Range of Adverse Effects}

AEs described in this article are those which are encountered most frequently. However, the full range of AEs that have been detected in or described by persons who have taken TQ either for prophylaxis or for radical cure is covered by recent reviews. ${ }^{82-89}$ Infrequent AEs are also specified in some of the other papers cited, particularly those referenced in Tables 1-3.

\section{Safety for Prophylaxis}

The most common AEs $(\geq 1 \%)$ when TQ is used for malaria prophylaxis are headache, dizziness, nausea, vomiting, motion sickness, diarrhea, abnormal dreams, insomnia, anxiety, depression, back pain, and an increased alanine transaminase (ALT) level. ${ }^{90}$

AEs that were often recorded in clinical trials (trials not already mentioned in the "Adverse Events" section) for individuals who took TQ prophylactically are listed in Tables 1 and 2, together with associated dosages.

\section{Safety for Radical Cure}

The most common AEs ( $\geq 5 \%$ ) when TQ is used for radical cure are headache, dizziness, nausea, vomiting, and a decreased hemoglobin level. ${ }^{91}$ 
Table 3 Common Adverse Events (Regardless of Causality) in Some Radical Cure Studies, Correlated with Tafenoquine Dosage (Information from Papers Additional to Those Cited in the "Adverse Events" Section)

\begin{tabular}{|c|c|c|c|}
\hline Adverse Event Details & Drug Dosage & $\begin{array}{l}\text { Number of } \\
\text { Individuals }\end{array}$ & $\begin{array}{l}\text { Reference } \\
\text { Number }\end{array}$ \\
\hline $\begin{array}{l}\text { AEs (mild and infrequent): dizziness; headache; heartburn/gas; } \\
\text { diarrhea; vomiting; eye irritation (once, perhaps TQ-unrelated) }\end{array}$ & Up to $600 \mathrm{mg}$ & 48 & [109] \\
\hline $\begin{array}{l}\text { AEs occurred in a minority of patients in all treatment groups: mainly } \\
\text { abdominal discomfort; diarrhea or loose stools; nausea; headache }\end{array}$ & $\begin{array}{l}\text { A: } 300 \mathrm{mg} / \mathrm{d} \text { for } 7 \mathrm{~d} ; \mathrm{B}: 500 \mathrm{mg} / \mathrm{d} \text { for } 3 \\
\mathrm{~d}+\mathrm{I} \mathrm{w} \text { after } \text { I }^{\text {st }} \text { dose, } 500 \mathrm{mg} / \mathrm{d} \text { for } 3 \\
\text { more d; C: } 500 \mathrm{mg} \text { (single dose) }\end{array}$ & $\begin{array}{l}A 15+B I I \\
+C 9=\text { total } \\
35\end{array}$ & {$[110]$} \\
\hline $\begin{array}{l}\text { AEs (mild and transient): mainly abdominal discomfort; diarrhea or } \\
\text { loose stools; nausea; dizziness; headache; weakness }\end{array}$ & $\begin{array}{l}\text { A: } 300 \mathrm{mg} / \mathrm{d} \text { for } 7 \mathrm{~d} ; \mathrm{B}: 600 \mathrm{mg} / \mathrm{d} \text { for } 3 \mathrm{~d} \text {; } \\
\text { C: } 600 \mathrm{mg} \text { (single dose) }\end{array}$ & $\begin{array}{l}\text { A } 18+B 19 \\
+C 18= \\
\text { total } 55\end{array}$ & {$[111]$} \\
\hline $\begin{array}{l}\geq 5 \% \text { AEs: headache 29; chills 16; diarrhea 16; pyrexia 13; upper } \\
\text { abdominal pain II; nausea 9; weakness 9; dizziness 7; parasitic } \\
\text { gastroenteritis 7; back pain 7; arthralgia 5; insomnia 5; myalgia 5; } \\
\text { vomiting 5; increased alanine transaminase level } 5\end{array}$ & $\begin{array}{l}600 \mathrm{mg} \text { (highest single dose tested) + } \\
\mathrm{CQ} \text { for } 3 \mathrm{~d}\end{array}$ & 56 & [112] \\
\hline $\begin{array}{l}\geq 5 \% \text { AEs: methemoglobinemia } 47.8 \text {; keratopathy } 31.8 \text {; headache } 30.4 \text {; } \\
\text { URTI 30.4; dizziness } 26.1 \text {; retinopathy/retinal disorder } 22.7 \text {; } \\
\text { eosinophilia I7.4; abdominal pain } 13.0 \text {; nausea } 13.0 \text {; thrombocytopenia } \\
\text { I3.0; pyrexia 10.9; asthenia } 8.7 \text {; diarrhea } 6.5 \text {; dyspepsia } 6.5 \text {; } \\
\text { hepatomegaly } 6.5 \text {; hypokalemia } 6.5 \text {; myalgia } 6.5\end{array}$ & $400 \mathrm{mg} / \mathrm{d}$ for $3 \mathrm{~d}$ & 46 & [113] \\
\hline $\begin{array}{l}\geq 5 \% \text { AEs: pruritus II.2; dizziness } 8.5 \text {; nausea } 6.2 \text {; vomiting } 5.8 \text {; } \\
\text { decreased hemoglobin level } 5.4\end{array}$ & $300 \mathrm{mg}$ (single dose) $+\mathrm{CQ}$ for $3 \mathrm{~d}$ & 260 & [114] \\
\hline $\begin{array}{l}\geq 5 \% \text { AEs: dizziness } 16.3 \text {; pruritus } 12.0 \text {; headache II.4; nausea 9.6; } \\
\text { vomiting } 6.6\end{array}$ & $300 \mathrm{mg}$ (single dose) $+\mathrm{CQ}$ for $3 \mathrm{~d}$ & 166 & [115] \\
\hline
\end{tabular}

Notes: The figures for adverse events (AEs) are percentages. AEs that have frequently been recorded are shown. For the full range of possible AEs, see the paper concerned.

Abbreviations: $A E$, adverse event; $C Q$, chloroquine; $d$, day(s); mg, milligrams; URTI, upper respiratory tract infection; w, week.

AEs that were often recorded in clinical trials (trials not already mentioned in the "Adverse Events" section) for individuals who took TQ for radical cure are listed in Table 3, together with associated dosages.

\section{Efficacy for Prophylaxis}

Leaving aside the different dosages used, ${ }^{85}$ protective TQ efficacy percentages of between $85.6 \%$ and $100 \%$ have been calculated. ${ }^{82,85}$

In a recent paper on TQ usage for malaria prophylaxis, Islam et al ${ }^{92}$ reported that a loading dose alone $(200 \mathrm{mg}$ daily for three days), in other words not followed by any additional doses, was effective in preventing malaria in short-term travelers (meaning a trip duration of less than 28 days). It may be that sporozoites inoculated by a mosquito ${ }^{12}$ are inactivated by TQ before hepatic schizogony can commence. This lower intake of TQ may also have meant fewer AEs. Longer-term monitoring for at least six months is required to see whether these short-term travelers do indeed continue to remain malaria-free. $^{92}$

\section{Efficacy for Radical Cure}

A single $300 \mathrm{mg}$ dose of TQ for radical cure prevented recurrence of $P$. vivax malaria over a 6-month period in $62 \%$ to $89 \%$ of cases. ${ }^{85}$ The efficacy profile of TQ is in general similar to that of primaquine, although some variability geographically has been detected. Also, there has been inconsistency in trial findings in South-East Asia (as discussed by Llanos-Cuentas et al in the last paper covered in Table 3). A possible future course of action might be to reassess the currently recommended $300 \mathrm{mg}$ dose of TQ in respect of parts of Oceania, South America and South-East $\mathrm{Asia}^{73}$ because so far, it seems that this TQ dose is not always sufficiently effective in those regions.

St Jean et $\mathrm{al}^{93}$ have carried out initial research into the pharmacogenetics of TQ efficacy in treating P. vivax 
malaria. TQ efficacy was found to be correlated with particular patient genotypes, although it is unclear at this stage whether these were spurious connections. Further study is needed. ${ }^{93}$

\section{Recommended Partner Drug for Tafenoquine}

It is at present recommended that TQ be administered together with chloroquine, specifically, as the partner drug. ${ }^{74,94}$ This differs from previous advice. ${ }^{74}$ The change is because of a low efficacy finding when patients in Indonesia were treated with a combination of TQ and dihydroartemisinin-piperaquine for the prevention of $P$. vivax malarial recurrences. ${ }^{95}$ The reason(s) for the low efficacy is not readily apparent. An account of the study was given in 2020 at the 69th Annual Meeting of the American Society of Tropical Medicine and Hygiene but full details have not yet been published, so the matter cannot be discussed here. It has in the meantime been argued, in relation to the research, that the currently recommended dose of TQ might be too low. ${ }^{96}$ Perhaps this hypothesis will be followed up in due course, depending partly upon what information becomes available in the meantime.

\section{Tafenoquine in Children}

TQ is not advised for prophylaxis in children under 18 or for radical cure in patients under 16 . However, the safety and efficacy of TQ for children has been under investigation. On the basis of a pharmacokinetic bridging modeling study for the radical cure indication, ${ }^{97}$ the Australian Therapeutic Goods Administration (TGA) has accepted a filing for the use of TQ for radical cure in children. ${ }^{98}$ Further developments are awaited.

\section{Tafenoquine in Pregnancy}

As previously mentioned, TQ is not recommended for pregnant women. ${ }^{90,91}$

\section{Drug Injection}

To overcome or reduce the risk of hemolysis because of G6PD deficiency, Srinivasan et $\mathrm{al}^{99}$ have given initial consideration to the idea of a non-oral route of drug administration, based on the assumption that TQ acts against hypnozoites. Murine experiments with $P$. berghei showed that there was reduced drug-associated hemotoxicity when compounds were not administered via the gastrointestinal tract. Outstanding bioavailability was achieved subcutaneously using liver-targeted TQ polymer prodrugs ("drugamers"). The ultimate goal of this ongoing research is to produce a single-dose subcutaneous therapeutic that eliminates hypnozoites but has minimal hemotoxicity in G6PD-deficient humans. ${ }^{99}$

\section{Conclusion}

This article is a synopsis of current knowledge about the safety and efficacy of TQ for $P$. vivax malaria prophylaxis and radical cure. It covers some new TQ-associated findings reported in papers published in 2020 and 2021. It also draws attention to relevant theoretical and terminological considerations that are often overlooked.

\section{Funding}

No specific funding was received for writing this paper.

\section{Disclosure}

The author declares that he has no conflicts of interest, financial or otherwise.

\section{References}

1. Lu K-Y, Derbyshire ER. Tafenoquine: a step toward malaria elimination. Biochemistry. 2020;59(8):911-920. doi:10.1021/acs. biochem.9b01105

2. Zottig VE, Carr KA, Clarke JG, Shmuklarsky MJ, KreishmanDeitrick M. Army antimalarial drug development: an advanced development case study for tafenoquine. Mil Med. 2020;185 (Suppl 1):617-623. doi:10.1093/milmed/usz304

3. Markus MB. Terminology for invasive stages of protozoa of the subphylum Apicomplexa (Sporozoa). S Afr $\quad J \quad$ Sci. 1978;74 (3):105-106.

4. Markus MB. The malarial hypnozoite. Lancet. 1980;315 (8174):936. doi:10.1016/s0140-6736(80)90871-5

5. Markus MB. Malaria: origin of the term "hypnozoite". $J$ Hist Biol. 2011;44(4):781-786. doi:10.1007/s10739-010-9239-3

6. Markus MB. Possible support for the sporozoite hypothesis of relapse and latency in malaria. Trans $R$ Soc Trop Med Hyg. 1976;70(5-6):535. doi:10.1016/0035-9203(76)90153-X

7. Markus MB. The hypnozoite concept, with particular reference to malaria. Parasitol Res. 2011;108(1):247-252. doi:10.1007/ s00436-010-2072-y

8. Voorberg-van der Wel AM, Zeeman A-M, Nieuwenhuis IG, et al. A dual fluorescent Plasmodium cynomolgi reporter line reveals in vitro malaria hypnozoite reactivation. Commun Biol. 2020;3:7. doi:10.1038/s42003-019-0737-3

9. Markus MB. Transition from plasmodial hypnozoite to schizont demonstrated. Trends Parasitol. 2020;36(5):407-408. doi:10.1016/j.pt.2020.01.011

10. Schäfer C, Zanghi G, Vaughan AM, Kappe SHI. Plasmodium vivax latent liver stage infection and relapse: biological insights and new experimental tools. Аnпи Rev Microbiol. 2021;75. doi:10.1146/annurev-micro-032421-061155

11. Ménard R, Tavares J, Cockburn I, Markus M, Zavala F, Amino R. Looking under the skin: the first steps in malarial infection and immunity. Nat Rev Microbiol. 2013;11(10):701-712. doi:10.1038/ nrmicro3111 
12. Markus MB. Dormancy of plasmodial sporozoites; 2019. Available from: www.researchgate.net/publication/337548652 Dormancy-of-Plasmodial-Sporozoites. Accessed June 30, 2021.

13. Franken G, Richter J, Labisch A. Can we be sure that the human Plasmodium exoerythrocytic developmental stages occur exclusively in the liver? Parasitol Res. 2020;119(2):667-673. doi:10.1007/s00436-019-06564-8

14. Meibalan E, Barry A, Gibbins MP, et al. Plasmodium falciparum gametocyte density and infectivity in peripheral blood and skin tissue of naturally infected parasite carriers in Burkina Faso. J Infect Dis. 2021;223(10):1822-1830. doi:10.1093/infdis/jiz680

15. Gueirard P, Tavares J, Thiberge S, et al. Development of the malaria parasite in the skin of the mammalian host. Proc Natl Acad Sci USA. 2010;107(43):18640-18645. doi:10.1073/pnas.1009346107

16. Voza T, Miller JT, Kappe SHI, Sinnis P. Extrahepatic exoerythrocytic forms of rodent malaria parasites at the site of inoculation: clearance after immunization, susceptibility to primaquine, and contribution to blood-stage infection. Infect Immun. 2012;80 (6):2158-2164. doi:10.1128/IAI.00246-12

17. Markus MB. New evidence for hypnozoite-independent Plasmodium vivax malarial recurrences. Trends Parasitol. 2018;34(12):1015-1016. doi:10.1016/j.pt.2018.08.010

18. Battle KE, Lucas TCD, Nguyen M, et al. Mapping the global endemicity and clinical burden of Plasmodium vivax, 2000-17: a spatial and temporal modelling study. Lancet. 2019;394 (10195):332-343. doi:10.1016/S0140-6736(19)31096-7

19. Flannery EL, Markus MB, Vaughan AM. Plasmodium vivax. Trends Parasitol. 2019;35(7):583-584. doi:10.1016/j.pt.2019.04.005

20. Cui L, Brashear A, Menezes L, Adams J. Elimination of Plasmodium vivax malaria: problems and solutions. In: Rodriguez-Morales AJ, editor. Current Topics and Emerging Issues in Malaria Elimination. IntechOpen; 2021:1-27. doi:10.5772/intechopen.96604

21. Sato S. Plasmodium - a brief introduction to the parasites causing human malaria and their basic biology. $J$ Physiol Anthropol. 2021;40(1):1. doi:10.1186/s40101-020-00251-9

22. Sutherland CJ, Tanomsing N, Nolder D, et al. Two nonrecombining sympatric forms of the human malaria parasite Plasmodium ovale occur globally. J Infect Dis. 2010;201(10):1544-1550. doi:10.1086/652240

23. Richter J, Franken G, Mehlhorn H, Labisch A, Häussinger D. What is the evidence for the existence of Plasmodium ovale hypnozoites? Parasitol Res. 2010;107(6):1285-1290. doi:10.1007/s00436-010-2071-z

24. Soulard V, Bosson-Vanga H, Lorthiois A, et al. Plasmodium falciparum full life cycle and Plasmodium ovale liver stages in humanized mice. Nat Commun. 2015;6:7690. doi:10.1038/ ncomms 8690

25. Markus MB. Mouse-based research on quiescent primate malaria parasites. Trends Parasitol. 2016;32(4):271-273. doi:10.1016/j. pt.2016.02.006

26. Richter J, Franken G, Holtfreter MC, Walter S, Labisch A, Mehlhorn H. Clinical implications of a gradual dormancy concept in malaria. Parasitol Res. 2016;115(6):2139-2148. doi:10.1007/ s00436-016-5043-0

27. Groger M, Fischer HS, Veletzky L, Lalremruata A, Ramharter M. A systematic review of the clinical presentation, treatment and relapse characteristics of human Plasmodium ovale malaria. Malar J. 2017;16:112. doi:10.1186/s12936-017-1759-2

28. Groger M, Veletzky L, Lalremruata A, et al. Prospective clinical and molecular evaluation of potential Plasmodium ovale curtisi and wallikeri relapses in a high-transmission setting. Clin Infect Dis. 2019;69(12):2119-2126. doi:10.1093/cid/ciz131
29. Wångdahl $\mathrm{A}$, Sondén $\mathrm{K}$, Wyss K, et al. Relapse of Plasmodium vivax and Plasmodium ovale malaria with and without primaquine treatment in a nonendemic area. Clin Infect Dis. 2021; ciab610. doi:10.1093/cid/ciab610

30. Markus MB. Malaria eradication and the hidden parasite reservoir. Trends Parasitol. 2017;33(7):492-495. doi:10.1016/j. pt.2017.03.002

31. Markus MB. Biological concepts in recurrent Plasmodium vivax malaria. Parasitology. 2018;145(13):1765-1771. doi:10.1017/ S003118201800032X

32. Markus MB. Plasmodium: yet more don'ts. Trends Parasitol. 2019;35(2):101-102. doi:10.1016/j.pt.2018.11.006

33. McFadden GI. Plasmodia - don't. Trends Parasitol. 2012;28 (8):306. doi:10.1016/j.pt.2012.05.006

34. Markus MB. Killing of Plasmodium vivax by primaquine and tafenoquine. Trends Parasitol. 2019;35(11):857-859. doi:10.1016/j.pt.2019.08.009

35. Kho S, Qotrunnada L, Leonardo L, et al. Hidden biomass of intact malaria parasites in the human spleen. New Engl J Med. 2021;384 (21):2067-2069. doi:10.1056/NEJMc2023884

36. Kho S, Qotrunnada L, Leonardo L, et al. Evaluation of splenic accumulation and colocalization of immature reticulocytes and Plasmodium vivax in asymptomatic malaria: a prospective human splenectomy study. PLoS Med. 2021;18(5):e1003632. doi:10.1371/journal.pmed.1003632

37. Woodford J, Gillman A, Jenvey P, et al. Positron emission tomography and magnetic resonance imaging in experimental human malaria to identify organ-specific changes in morphology and glucose metabolism: a prospective cohort study. PLoS Med. 2021;18(5):e1003567. doi:10.1371/journal.pmed.1003567

38. Barber BE, William T, Grigg MJ, et al. Parasite biomass-related inflammation, endothelial activation, microvascular dysfunction and disease severity in vivax malaria. PLoS Pathog. 2015;11(1): e1004558. doi:10.1371/journal.ppat.1004558

39. Mayor A, Alano P. Bone marrow reticulocytes: a Plasmodium vivax affair? Blood. 2015;125(8):1203-1205. doi:10.1182/blood2014-12-614123

40. Obaldia N 3rd, Meibalan E, Sa JM, et al. Bone marrow is a major parasite reservoir in Plasmodium vivax infection. mBio. 2018;9 (3):e00625-18. doi:10.1128/mBio.00625-18

41. Peterson MS, Joyner CJ, Cordy RJ, et al. Plasmodium vivax parasite load is associated with histopathology in Saimiri boliviensis with findings comparable to $P$. vivax pathogenesis in humans. Open Forum Infect Dis. 2019;6(3):ofz021. doi:10.1093/ ofid/ofz021

42. Brito MAM, Baro B, Raiol TC, et al. Morphological and transcriptional changes in human bone marrow during natural Plasmodium vivax malaria infections. $J$ Infect Dis. 2020; jiaa177. doi:10.1093/infdis/jiaa177

43. Shaikh MS, Ali B, Janjua M, et al. Plasmodium in the bone marrow: case series from a hospital in Pakistan, 2007-2015. Malar J. 2021;20:254. doi:10.1186/s12936-021-03792-1

44. Markus MB. Source of clinical malaria in mixed-species infections. J Travel Med. 2012;19(4):275. doi:10.1111/j.17088305.2012.00622.x

45. Camarda G, Jirawatcharadech P, Priestley RS, et al. Antimalarial activity of primaquine operates via a two-step biochemical relay. Nat Commun. 2019;10:3226. doi:10.1038/ s41467-019-11239-0

46. Dow GS, Gettayacamin M, Hansukjariya P, et al. Radical curative efficacy of tafenoquine combination regimens in Plasmodium cynomolgi-infected rhesus monkeys (Macaca mulatta). Malar J. 2011;10:212. doi:10.1186/1475-2875-10-212 
47. Dembélé L, Franetich J-F, Soulard V, et al. Chloroquine potentiates primaquine activity against active and latent hepatic plasmodia ex vivo: potentials and pitfalls. Antimicrob Agents Chemother. 2021;65(1):e01416-20. doi:10.1128/AAC.01416-20

48. Maher S, Vantaux A, Chaumeau V, et al. Probing the distinct chemosensitivity of Plasmodium vivax liver stage parasites and demonstration of 8-aminoquinoline radical cure activity in vitro. Res Sq. 2021. doi:10.21203/rs.3.rs-185180/v1

49. Balieiro AAS, Siqueira AM, Melo GC, et al. Short-time recurrences of Plasmodium vivax malaria as a public health proxy for chloroquine-resistance surveillance: a spatio-temporal study in the Brazilian Amazon. Int $J$ Environ Res Public Health. 2021;18:5061. doi:10.3390/ijerph18105061

50. Ferreira MU, de Sousa TN, Rangel GW, et al. Monitoring Plasmodium vivax resistance to antimalarials: persisting challenges and future directions. Int J Parasitol Drugs Drug Resist. 2021;15:9-24. doi:10.1016/j.ijpddr.2020.12.001

51. Rovira-Vallbona E, Van Hong N, Kattenberg JH, et al. High proportion of genome-wide homology and increased pretreatment pvcrt levels in Plasmodium vivax late recurrences: a chloroquine therapeutic efficacy study. Antimicrob Agents Chemother. 2021;65(8):e009521. doi:10.1128/AAC.00095-21

52. Freese JA, Markus MB, Golenser J. In vitro sensitivity of southern African reference isolates of Plasmodium falciparum to chloroquine and pyrimethamine. Bull World Health Organ. 1991;69 (6):707-712. PMID: 1786619.

53. McCutcheon KRG, Freese JA, Frean JA, Veale RB, Sharp BL, Markus MB. Chloroquine-resistant isolates of Plasmodium falciparum with alternative CG2 omega repeat length polymorphisms. Am J Trop Med Hyg. 2000;62(2):190-192. doi:10.4269/ ajtmh.2000.62.190

54. Sutherland CJ. Persistent parasitism: the adaptive biology of malariae and ovale malaria. Trends Parasitol. 2016;32 (10):808-819. doi:10.1016/j.pt.2016.07.001

55. Lover AA, Baird JK, Gosling R, Price RN. Malaria elimination: time to target all species. Am J Trop Med Hyg. 2018;99(1):17-23. doi:10.4269/ajtmh.17-0869

56. Grande R, Antinori S, Meroni L, Menegon M, Severini C. A case of Plasmodium malariae recurrence: recrudescence or reinfection? Malar J. 2019;18:169. doi:10.1186/s12936-019-2806-y

57. Markus MB. Dormancy in mammalian malaria. Trends Parasitol. 2012;28(2):39-45. doi:10.1016/j.pt.2011.10.005

58. Markus MB. Do hypnozoites cause relapse in malaria? Trends Parasitol. 2015;31(6):239-245. doi:10.1016/j. pt.2015.02.003

59. Dow G, Smith B. The blood schizonticidal activity of tafenoquine makes an essential contribution to its prophylactic efficacy in nonimmune subjects at the intended dose (200 mg). Malar J. 2017;16:209. doi:10.1186/s12936-017-1862-4

60. McCarthy JS, Smith B, Reid M, et al. Blood schizonticidal activity and safety of tafenoquine when administered as chemoprophylaxis to healthy, nonimmune participants followed by blood stage Plasmodium falciparum challenge: a randomized, double-blind, placebo-controlled phase 1b study. Clin Infect Dis. 2019;69(3):480-486. doi:10.1093/cid/ciy939

61. World Health Organization. WHO guidelines for malaria; 2021. Available from: https://www.who.int/publications/i/item/guide lines-for-malaria. Accessed June 30, 2021.

62. Luzzatto L, Ally M, Notaro R. Glucose-6-phosphate dehydrogenase deficiency. Blood. 2020;136(11):1225-1240. doi:10.1182/ blood.2019000944

63. Brito-Sousa JD, Murta F, Vitor-Silva S, et al. Real-life implementation of a G6PD deficiency screening qualitative test into routine vivax malaria diagnostic units in the Brazilian Amazon (SAFEPRIM study). PLoS Negl Trop Dis. 2021;15(5):e0009415. doi:10.1371/journal.pntd.0009415
64. Gerth-Guyette E, Adissu W, Brito M, et al. Usability of a point-of-care diagnostic to identify glucose-6-phosphate dehydrogenase deficiency: a multi-country assessment of test label comprehension and results interpretation. Malar J. 2021;20:307. doi:10.1186/s12936-021-03803-1

65. Thriemer K, Ley B, von Seidlein L. Towards the elimination of Plasmodium vivax malaria: implementing the radical cure. PLoS Med. 2021;18(4):e1003494. doi:10.1371/journal.pmed.1003494

66. Chu CS, Bancone G, Kelley M, et al. Optimizing G6PD testing for Plasmodium vivax case management and beyond: why sex, counseling, and community engagement matter. Wellcome Open Res. 2020;5:21. doi:10.12688/wellcomeopenres.15700.2

67. Commons RJ, McCarthy JS, Price RN. Tafenoquine for the radical cure and prevention of malaria: the importance of testing for G6PD deficiency. Med J Aust. 2020;212(4):152-153.e1. doi:10.5694/mja2.50474

68. Swastika M, Harahap AR, Panggalo LV, Jusman SWA, Satyagraha AW. Determining a critical threshold for G6PD activity below which red blood cell response to oxidative stress is poor. Malar J. 2020;19:208. doi:10.1186/s12936-020-03272-y

69. Calvaresi EC, Genzen JR. Evaluating percentage-based reporting of glucose-6-phosphate dehydrogenase (G6PD) enzymatic activity: assessment of patient eligibility for malaria prevention and treatment with tafenoquine. Am J Clin Pathol. 2020;154 (2):248-254. doi:10.1093/ajcp/aqaa040

70. Pfeffer DA, Ley B, Howes RE, et al. Quantification of glucose-6-phosphate dehydrogenase activity by spectrophotometry: a systematic review and meta-analysis. PLoS Med. 2020;17 (5):e1003084. doi:10.1371/journal.pmed.1003084

71. Boonyuen U, Songdej D, Tanyaratsrisakul S, et al. Glucose6-phosphate dehydrogenase mutations in malaria endemic area of Thailand by multiplexed high-resolution melting curve analysis. Malar J. 2021;20:194. doi:10.1186/s12936-021-03731-0

72. Chamchoy K, Praoparotai A, Pakparnich P, et al. The integrity and stability of specimens under different storage conditions for glucose-6-phosphate dehydrogenase deficiency screening using WST-8. Acta Trop. 2021;217:105864. doi:10.1016/j. actatropica.2021.105864

73. Chu CS, Hwang J. Tafenoquine: a toxicity overview. Expert Opin Drug Saf. 2021;20(3):349-362. doi:10.1080/14740338.2021.1859476

74. Labels for Krintafel. U.S. Food \& Drug Administration; 2020. Available from: https:/www.accessdata.fda.gov/scripts/cder/daf/ index.cfm? event $=$ overview.process \&applno $=210795$. Accessed June 30, 2021.

75. Berman J, Brown T, Dow G, Toovey S. Tafenoquine and primaquine do not exhibit clinical neurologic signs associated with central nervous system lesions in the same manner as earlier 8-aminoquinolines. Malar J. 2018;17:407. doi:10.1186/s12936-018-2555-3

76. Duparc S, Chalon S, Miller S, Richardson N, Toovey S. Neurological and psychiatric safety of tafenoquine in Plasmodium vivax relapse prevention: a review. Malar J. 2020;19:111. doi:10.1186/s12936-020-03184-x

77. Ackert J, Mohamed K, Slakter JS, et al. Randomized placebo-controlled trial evaluating the ophthalmic safety of single-dose tafenoquine in healthy volunteers. Drug Saf. 2019;42(9):1103-1114. doi:10.1007/s40264-019-00839-w

78. Warrasak S, Euswas A, Fukuda MM, et al. Comparative ophthalmic assessment of patients receiving tafenoquine or chloroquine/ primaquine in a randomized clinical trial for Plasmodium vivax malaria radical cure. Int Ophthalmol. 2019;39(8):1767-1782. doi:10.1007/s10792-018-1003-2

79. Leary KJ, Riel MA, Roy MJ, et al. A randomized, double-blind, safety and tolerability study to assess the ophthalmic and renal effects of tafenoquine $200 \mathrm{mg}$ weekly versus placebo for 6 months in healthy volunteers. Am J Trop Med Hyg. 2009;81 (2):356-362. doi:10.4269/ajtmh.2009.81.356 
80. Miller AK, Harrell E, Ye L, et al. Pharmacokinetic interactions and safety evaluations of coadministered tafenoquine and chloroquine in healthy subjects. Br J Clin Pharmacol. 2013;76 (6):858-867. doi:10.1111/bcp.12160

81. Green JA, Patel AK, Patel BR, et al. Tafenoquine at therapeutic concentrations does not prolong Fridericia-corrected QT interval in healthy subjects. J Clin Pharmacol. 2014;54(9):995-1005. doi: $10.1002 /$ jcph.302

82. Maier JD, Siegfried S, Gültekin N, et al. Efficacy and safety of tafenoquine for malaria chemoprophylaxis (1998-2020): a systematic review and meta-analysis. Travel Med Infect Dis. 2021;39:101908. doi:10.1016/j.tmaid.2020.101908

83. Anjum MU, Naveed AK, Mahmood SN, Naveed OK. Single dose tafenoquine for preventing relapse in people with Plasmodium vivax malaria - an updated meta-analysis. Travel Med Infect Dis. 2020;36:101576. doi:10.1016/j.tmaid.2020.101576

84. Chen V, Daily JP. Tafenoquine: the new kid on the block. Curr Opin Infect Dis. 2019;32(5):407-412. doi:10.1097/QCO.0000 000000000574

85. Haston JC, Hwang J, Tan KR. Guidance for using tafenoquine for prevention and antirelapse therapy for malaria - United States, 2019. Morb Mortal Wkly Rep. 2019;68(46):1062-1068. doi:10.15585/mmwr.mm6846a4

86. Hounkpatin AB, Kreidenweiss A, Held J. Clinical utility of tafenoquine in the prevention of relapse of Plasmodium vivax malaria: a review on the mode of action and emerging trial data. Infect Drug Resist. 2019;12:553-570. doi:10.2147/IDR. S151031

87. Novitt-Moreno A, Ransom J, Dow G, Smith B, Read LT, Toovey S. Tafenoquine for malaria prophylaxis in adults: an integrated safety analysis. Travel Med Infect Dis. 2017;17:19-27. doi:10.1016/j.tmaid.2017.05.008

88. Rodrigo C, Rajapakse S, Fernando D. Tafenoquine for preventing relapse in people with Plasmodium vivax malaria. Cochrane Database Syst Rev. 2020;9:CD010458. doi:10.1002/14651858. CD010458.pub3

89. Val F, Costa FTM, King L, et al. Tafenoquine for the prophylaxis, treatment and elimination of malaria: eagerness must meet prudence. Future Microbiol. 2019;14(15):1261-1279. doi:10.2217/fmb-2019-0202

90. Label for Arakoda. U.S. Food \& Drug Administration; 2018. Available from: https://www.accessdata.fda.gov/drugsatfda_docs/ label/2018/210607lbl.pdf. Accessed June 30, 2021.

91. Label for Krintafel. U.S. Food \& Drug Administration; 2018. Available from: https://www.accessdata.fda.gov/drugsatfda_docs/ label/2018/210795s000lbl.pdf. Accessed June 30, 2021.

92. Islam N, Wright $\mathrm{S}$, Lau CL, et al. Efficacy of a 3-day pretravel schedule of tafenoquine for malaria chemoprophylaxis: a network meta-analysis. J Travel Med. 2021;28(5):taab057. doi:10.1093/ $\mathrm{jtm} / \mathrm{taab} 057$

93. St Jean PL, Koh GCKW, Breton JJ, et al. Pharmacogenetic assessment of tafenoquine efficacy in patients with Plasmodium vivax malaria. Pharmacogenet Genomics. 2020;30(7):161-165. doi:10.1097/FPC.0000000000000407

94. Mace KE, Lucchi NW, Tan KR. Malaria surveillance - United States, 2017. Morb Mortal Wkly Rep Surveill Summ. 2021;70 (2):1-35. doi:10.15585/mmwr.ss7002a1

95. Baird JK, Sutanto I, Soebandrio A, et al. Evaluation of the efficacy and safety of tafenoquine co-administered with dihydroartemisinin-piperaquine for the radical cure (anti-relapse) of Plasmodium vivax malaria in Indonesia - INSPECTOR study. 69th Annual Meeting of the American Society of Tropical Medicine and Hygiene; 2020. Available from: https://www. abstractsonline.com/pp8/\#!/9181/presentation/1478. Accessed June 30, 2021.
96. Watson JA, Nekkab N, White M. Tafenoquine for the prevention of Plasmodium vivax malaria relapse. Lancet Microbe. 2021;2(5): e175-e176. doi:10.1016/S2666-5247(21)00062-8

97. Vélez ID, Tran H, Martin A, et al. A randomized, open-label, non-comparative, multicenter study to assess the pharmacokinetics, safety, and efficacy of tafenoquine in the treatment of pediatric subjects with Plasmodium vivax malaria (TEACH study). 69th Annual Meeting of the American Society of Tropical Medicine and Hygiene; 2020. Available from: https:// www.abstractsonline.com/pp8/\#!/9181/presentation/1479.

Accessed June 30, 2021.

98. Medicines for Malaria Venture. P. vivax Information Hub; 2021. Available from: https://www.vivaxmalaria.org/news/gsk-mmvfiling-for-kozenis-tafenoquine-in-paediatric-populations-withplasmodium-vivax-malaria. Accessed June 30, 2021.

99. Srinivasan S, Roy D, Chavas TEJ, et al. Liver-targeted polymeric prodrugs of 8-aminoquinolines for malaria radical cure. $J$ Control Release. 2021;331:213-227. doi:10.1016/j. jconrel.2020.12.046

100. Lell B, Faucher J-F, Missinou MA, et al. Malaria chemoprophylaxis with tafenoquine: a randomised study. Lancet. 2000;355 (9220):2041-2045. doi:10.1016/S0140-6736(00)02352-7

101. Shanks GD, Oloo AJ, Aleman GM, et al. A new primaquine analogue, tafenoquine (WR 238605), for prophylaxis against Plasmodium falciparum malaria. Clin Infect Dis. 2001;33 (12):1968-1974. doi:10.1086/324081

102. Edstein MD, Kocisko DA, Walsh DS, Eamsila C, Charles BG, Rieckmann KH. Plasma concentrations of tafenoquine, a new long-acting antimalarial agent, in Thai soldiers receiving monthly prophylaxis. Clin Infect Dis. 2003;37(12):1654-1658. doi:10.1086/ 379718

103. Hale BR, Owusu-Agyei S, Fryauff DJ, et al. A randomized, double-blind, placebo-controlled, dose-ranging trial of tafenoquine for weekly prophylaxis against Plasmodium falciparum. Clin Infect Dis. 2003;36(5):541-549. doi:10.1086/367542

104. Charles BG, Miller AK, Nasveld PE, Reid MG, Harris IE, Edstein MD. Population pharmacokinetics of tafenoquine during malaria prophylaxis in healthy subjects. Antimicrob Agents Chemother. 2007;51(8):2709-2715. doi:10.1128/AAC.01183-06

105. Nasveld PE, Edstein MD, Reid M, et al. Randomized, double-blind study of the safety, tolerability, and efficacy of tafenoquine versus mefloquine for malaria prophylaxis in nonimmune subjects. Antimicrob Agents Chemother. 2010;54 (2):792-798. doi:10.1128/AAC.00354-09

106. Nasveld P, Kitchener S, Edstein M, Rieckmann K. Comparison of tafenoquine (WR238605) and primaquine in the post-exposure (terminal) prophylaxis of vivax malaria in Australian Defence Force personnel. Trans $R$ Soc Trop Med Hyg. 2002;96 (6):683-684. doi:10.1016/s0035-9203(02)90351-2

107. Edstein MD, Nasveld PE, Kocisko DA, Kitchener SJ, Gatton ML, Rieckmann KH. Gender differences in gastrointestinal disturbances and plasma concentrations of tafenoquine in healthy volunteers after tafenoquine administration for post-exposure vivax malaria prophylaxis. Trans $R$ Soc Trop Med Hyg. 2007;101(3):226-230. doi:10.1016/j.trstmh.2006.04.003

108. Elmes NJ, Nasveld PE, Kitchener SJ, Kocisko DA, Edstein MD. The efficacy and tolerability of three different regimens of tafenoquine versus primaquine for post-exposure prophylaxis of Plasmodium vivax malaria in the Southwest Pacific. Trans R Soc Trop Med Hyg. 2008;102(11):1095-1101. doi:10.1016/j. trstmh.2008.04.024

109. Brueckner RP, Lasseter KC, Lin ET, Schuster BG. First-time-inhumans safety and pharmacokinetics of WR 238605, a new antimalarial. Am J Trop Med Hyg. 1998;58(5):645-649. doi:10.4269/ajtmh.1998.58.645 
110. Walsh DS, Looareesuwan S, Wilairatana P, et al. Randomized dose-ranging study of the safety and efficacy of WR 238605 (tafenoquine) in the prevention of relapse of Plasmodium vivax malaria in Thailand. $J$ Infect Dis. 1999;180(4):1282-1287. doi:10.1086/315034

111. Walsh DS, Wilairatana P, Tang DB, et al. Randomized trial of 3-dose regimens of tafenoquine (WR238605) versus low-dose primaquine for preventing Plasmodium vivax malaria relapse. Clin Infect Dis. 2004;39(8):1095-1103. doi:10.1086/424508

112. Llanos-Cuentas A, Lacerda MV, Rueangweerayut R, et al. Tafenoquine plus chloroquine for the treatment and relapse prevention of Plasmodium vivax malaria (DETECTIVE): a multicentre, double-blind, randomised, phase $2 \mathrm{~b}$ dose-selection study. Lancet. 2014;383(9922):1049-1058. doi:10.1016/S01406736(13)62568-4
113. Fukuda MM, Krudsood S, Mohamed K, et al. A randomized, double-blind, active-control trial to evaluate the efficacy and safety of a three day course of tafenoquine monotherapy for the treatment of Plasmodium vivax malaria. PLoS One. 2017;12(11): e0187376. doi:10.1371/journal.pone.0187376

114. Lacerda MVG, Llanos-Cuentas A, Krudsood S, et al. Single-dose tafenoquine to prevent relapse of Plasmodium vivax malaria. $N$ Engl J Med. 2019;380(3):215-228. doi:10.1056/NEJMoa1710775

115. Llanos-Cuentas A, Lacerda MVG, Hien TT, et al. Tafenoquine versus primaquine to prevent relapse of Plasmodium vivax malaria. $N$ Engl J Med. 2019;380(3):229-241. doi:10.1056/ NEJMoa1802537

\section{Publish your work in this journal}

Therapeutics and Clinical Risk Management is an international, peerreviewed journal of clinical therapeutics and risk management, focusing on concise rapid reporting of clinical studies in all therapeutic areas, outcomes, safety, and programs for the effective, safe, and sustained use of medicines. This journal is indexed on PubMed Central, CAS,
EMBase, Scopus and the Elsevier Bibliographic databases. The manuscript management system is completely online and includes a very quick and fair peer-review system, which is all easy to use. Visit http://www.dovepress.com/testimonials.php to read real quotes from published authors. 